\title{
Implementation of double-layer loaded on octagon microstrip yagi antenna
}

\author{
Kamelia Quzwain ${ }^{1}$, Alyani Ismail², Yudiansyah ${ }^{3}$, Nadia Media Rizka ${ }^{4}$, \\ Aisyah Novfitri ${ }^{5}$, Lia Hafiza ${ }^{6}$ \\ 1,3,4,5,6 Department of Telecommunication Engineering, Institut Teknologi Telkom Jakarta, Indonesia \\ ${ }^{2}$ Department of Computer and Communication Systems Engineering, Universiti Putra Malaysia, Malaysia
}

\begin{tabular}{l}
\hline Article Info \\
\hline Article history: \\
Received Jul 31, 2021 \\
Revised Sep 23, 2021 \\
Accepted Oct 29, 2021 \\
\hline
\end{tabular}

Keywords:

ISM band

Microstrip antenna

Multilayer

Photonic crystal

Yagi antenna

\begin{abstract}
A double-layer loaded on the octagon microstrip yagi antenna (OMYA) at 5.8 $\mathrm{GHz}$ industrial, scientific and medical (ISM) Band is investigated in this paper. The double-layer consist of two double positive (DPS) substrates. The OMYA is overlaid with a double-layer configuration were simulated, fabricated and measured. A good agreement was observed between the computed and measured results of the gain for this antenna. According to comparison results, it shows that $2.5 \mathrm{~dB}$ improvement of the OMYA gain can be obtained by applying the double-layer on the top of the OMYA. Meanwhile, the bandwidth of the measured OMYA with the double-layer is $14.6 \%$. It indicates that the double-layer can be used to increase the OMYA performance in term of gain and bandwidth.
\end{abstract}

This is an open access article under the CC BY-SA license.

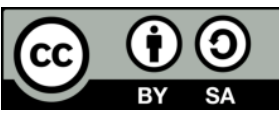

\section{Corresponding Author:}

Kamelia Quzwain

Department of Telecommunication Engineering

Institut Teknologi Telkom Jakarta

Daan Mogot KM.11, Cengkareng, West Jakarta 11710, Indonesia

Email: kamelia@ittelkom-jkt.ac.id

\section{INTRODUCTION}

Frequency of $5.8 \mathrm{GHz}$ is one of unlicensed frequencies which is used in low rate applications, for instance, sensor and radar [1]-[3]. Antennas play a vital role in wireless communication system. Microstrip patch antennas (MPAs) have some attractive advantages, such as easy fabrication, simplicity in design and lightweight. However, MPAs are associated with low gain [4]-[7]. Multilayer structure concept can be used to increase the gain of MPAs [8]-[11]. In addition, Yagi-Uda concept can be employed to tackle this limitation [12]. Several MPA-based Yagi-Uda concept have been introduced in [13]-[15].

In 2007, Dejean et al [13] reported a high gain microstrip Yagi antenna in order to improve the performance of the first microstrip Yagi antenna. The gain of their antenna is $10.7 \mathrm{~dB}$ with a size of $112 \mathrm{x}$ $112 \mathrm{~mm}^{2}$. Octagon microstip yagi antenna (OMYA) was introduced by Quzwain et al in [14]. Four octagon patches were successfully applied as driven elements to increase the performance in terms of bandwidth and gain without increasing the size of the antenna. This antenna is able to produce a gain of $11 \mathrm{~dB}$ with the surface size of $70 \mathrm{~mm} \times 75 \mathrm{~mm}$. As reported in literature [15], microstrip Yagi-Uda antenna can be constructed in a stacked-multilayer in order to minimize the size of the antenna. A gain of about $11 \mathrm{~dB}$ can be achieved through this design.

On the other side, numerous researchers in [16]-[18] were attracted to increase the gain of MPA by placing double positive (DPS) substrate above the MPA as a superstrate layer. An extra gain can be achieved by choosing the thicknesses of the DPS substrate and the superstrate layers properly. An interesting method 
to obtain more gain was introduced in [19] where the octagon fractal microstrip yagi antenna (OFMYA) is overlaid with a combined double negative (DNG) and DPS substrates as superstrate layer. To date, no previous experimental study has provided information on OMYA using double-layer. This paper introduces the OMYA using a doble-layer in order to improve the OMYA performance. Data for this investigations were collected based on simulation and experimental results. The paper is structured as; section 2 begins by giving an explanation of the proposed antenna design, the third section is concerned with the imulation and measurement results of the proposed antenna, the final section summarises the main findings of this research.

\section{ANTENNA DESIGN CONFIGURATION}

This Section explains the configuration of the proposed antenna design. The proposed antenna here is formed by one OMYA and two covers which are placed above the OMYA. The first stage is to consider the specifications of the proposed antenna based on its application as tabulated in Table 1.

Table 1. Antenna design parameters

\begin{tabular}{cc}
\hline Antenna Parameters & Values \\
\hline Frequency Range & $5.725 \mathrm{GHz}-5.875 \mathrm{GHz}$ \\
Centre Frequency & $5.8 \mathrm{GHz}$ \\
Bandwidth (BW) & $150 \mathrm{MHz}$ \\
VSWR & $\leq 2.0$ \\
Radiation Pattern & Broadside Directional \\
\hline
\end{tabular}

The proposed antenna in this paper comprises two double positive (DPS) substrates in which acts as superstrate layer. Figure 1 shows the OMYA structure which was first demonstrated experimentally by Quzwain et al [14]. The antenna was designed by using the same design rules as used in the conventional microstrip Yagi Uda antenna which is composed of a reflector element, a driven element and some director elements. Detailed explanations of the OMYA design can be found in [14]. The OMYA was fabricated on rogers 5880 with thickness of $1.575 \mathrm{~mm}$. The antenna consists of two reflector elements $\left(R_{t} \& R_{b}\right)$, one driven element $\left(D_{R}\right)$, two bottom director elements $\left(D_{1 b} \& D_{2 b}\right)$ and two top director elements $\left(D_{1 t} \& D_{2 t}\right)$.

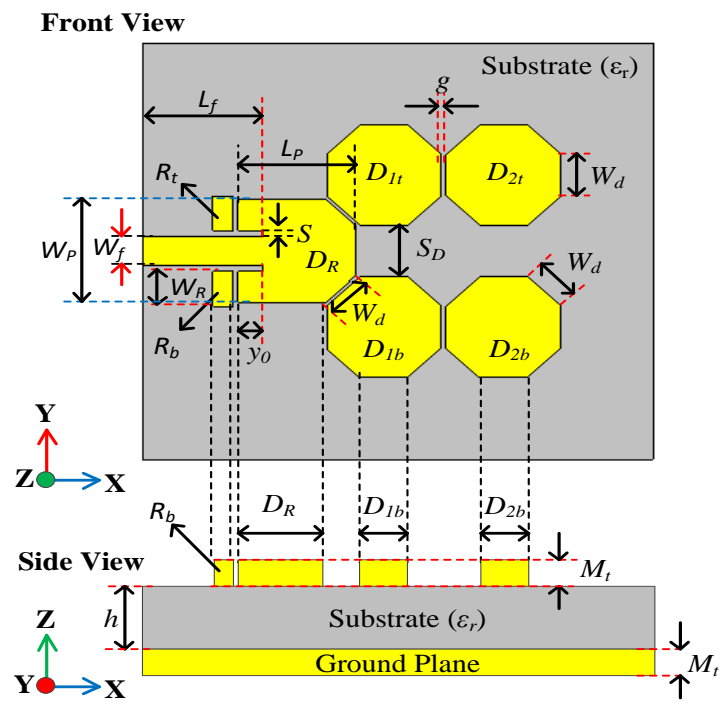

Figure 1. The OMYA geometry in [14]

A periodic structure of two or more DPS materials can be used to increase the gain. This arrangement is also called one-dimensional photonic crystal (1-D PCs) [20], [21]. It is the simplest structure among the three types of photonic crystal (PCs) in which comprises more than one DPS Material which is separated by air gap $\left(h_{3}\right)$ in periodic arrangement of $z$-axis as illustrated in Figure 2. This concept involves the addition of two high dielectric permittivity substrates on the top of the MPA [22], [23]. As shown in Figure 2, two additional substrates with dielectric permittivity of $\varepsilon_{r 2}$ and thickness of $t$ are placed above the 
antenna at height of $h_{2}$. The separation distance between two superstrate layers is $h_{3}$. Multiple superstrates method can be used to produce a narrow-beam radiation pattern when [24]:

$$
\frac{n_{0} h_{2}}{\lambda_{0}} \sqrt{1=\frac{\sin ^{2} \theta_{p}}{\left(n_{0}\right)^{2}}}=0.05
$$

and

$$
\frac{n_{1} t}{\lambda_{0}} \sqrt{1=\frac{\sin ^{2} \theta_{p}}{\left(n_{1}\right)^{2}}}=0.25
$$

Where $\theta_{P}$ is beam angle and the refraction of air $\left(n_{0}\right)$ equals to one and the refraction of superstrate $\left(n_{1}\right)$ can be determined as.

$$
n_{1}=\sqrt{\varepsilon_{1}} \mu_{1}
$$

Two Arlon AD1000 materials with $\varepsilon_{r}$ of 10.2 and thickness of $2.5 \mathrm{~mm}$ were used as DPS layer. A number of optimizations was done through CST Microwave Studio software in order to achieve the best result for gain based on $h_{2}$ and $h_{3}$ variation. The simulated gain results was observed in order to explore the relationship between the gain and the air gaps $\left(h_{2}\right.$ and $\left.h_{3}\right)$.

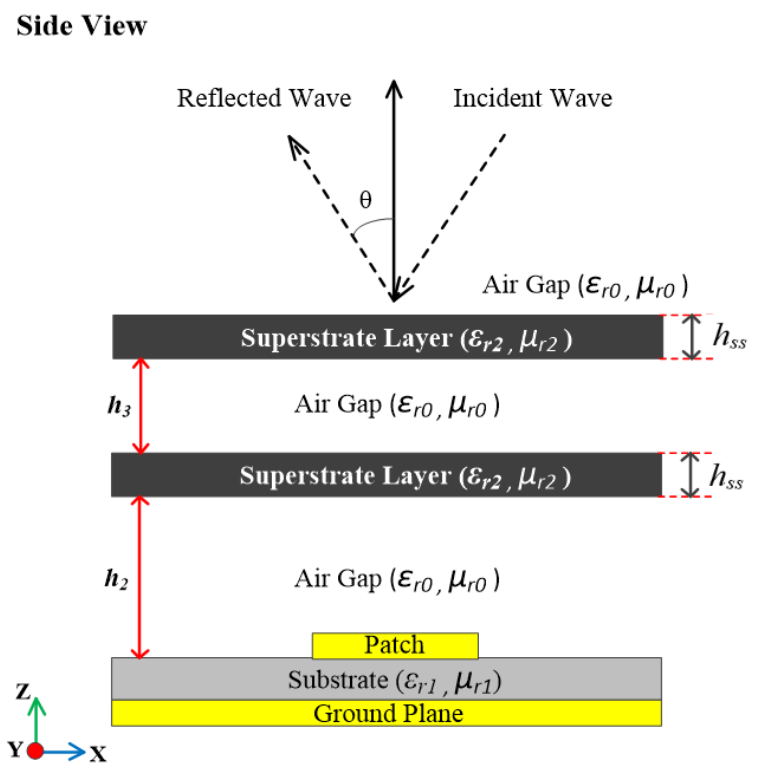

Figure 2. The designed OMYA with double DPS layer geometry

\section{RESULTS AND DISCUSSION}

In order to achieve a high gain and wide bandwidth, the OMYA was calculated and optimized by Quzwain et al in [14]. They explained that the side length of octagon-shaped $\left(W_{d}\right)$ and gap between parasitic elements $(g)$ give influence on gain and bandwidth of the OMYA. The first observation is the influence of placing single layer above the OMYA in order to examine the effect of the first air gap thickness $\left(h_{2}\right)$ and superstrate thickness $\left(h_{s s}\right)$ on gain. In this stage, the single-superstrate was moved vertically to the top with different superstrate thickness. The variation of the gain with respect to the first air gap thickness $\left(h_{2}\right)$ for different superstrate thickness $\left(h_{s s}\right)$ is shown in Figure 3. In this simulation result, it shows that a maximum gain of $12.42 \mathrm{~dB}$ can be obtained through this design where the optimum $h_{s s}$ for the maximum gain is 2.54 $\mathrm{mm}$ at $h_{2}$ of $31 \mathrm{~mm}$.

It is also clearly seen that the gain moves downward as the $h_{s s}$ value decreases. The graph also shows that the gain rise slightly between $h_{2}$ of $25 \mathrm{~mm}$ and $h_{2}$ of $31 \mathrm{~mm}$ and then decreases slightly. From this simulation result, it can be summarized that the gain of the OMYA can be enhanced up to $1.22 \mathrm{~dB}$ by adding single-layer configuration above the OMYA. Additionally, it proves that a thick superstrate is capable of

Implementation of double-layer loaded on octagon microstrip yagi antenna (Kamelia Quzwain) 
increasing the gain. Placing double-layer above the OMYA is the final stage in antenna design. In this stage, two crucial factors influencing the gain frequency characteristics; $h_{2}$ and $h_{3}$. In order to further investigate the effect of $h_{2}$ and $h_{3}$ air gaps on the gain, this stage explores the gain variations with changing the $h_{2}$ value for different the $h_{3}$ value and keeping dielectric permittivity of the second superstrate $\left(\varepsilon_{r-2 S S}\right)$ equals to the dielectric permittivity of the first one $\left(\varepsilon_{r-1 S S}\right)$. Usually the superstrate is placed half-wavelength $\left(\lambda_{0} / 2\right)$ above the antenna [25] to enhance the gain. Therefore, the starting point of $h_{2}$ and $h_{S S}$ from the radiating patch of the OMYA is around $25 \mathrm{~mm}$. Then, the first air gap height of $h_{2}$ was optimized by varying the value of $h_{2}$ in order to achieve the maximum gain. On the other side, the thickness of second air gap $\left(h_{3}\right)$ was also optimized by moving the position of the second superstrate in $y$-axis which is started at $h_{3}$ of $1 \mathrm{~mm}$.

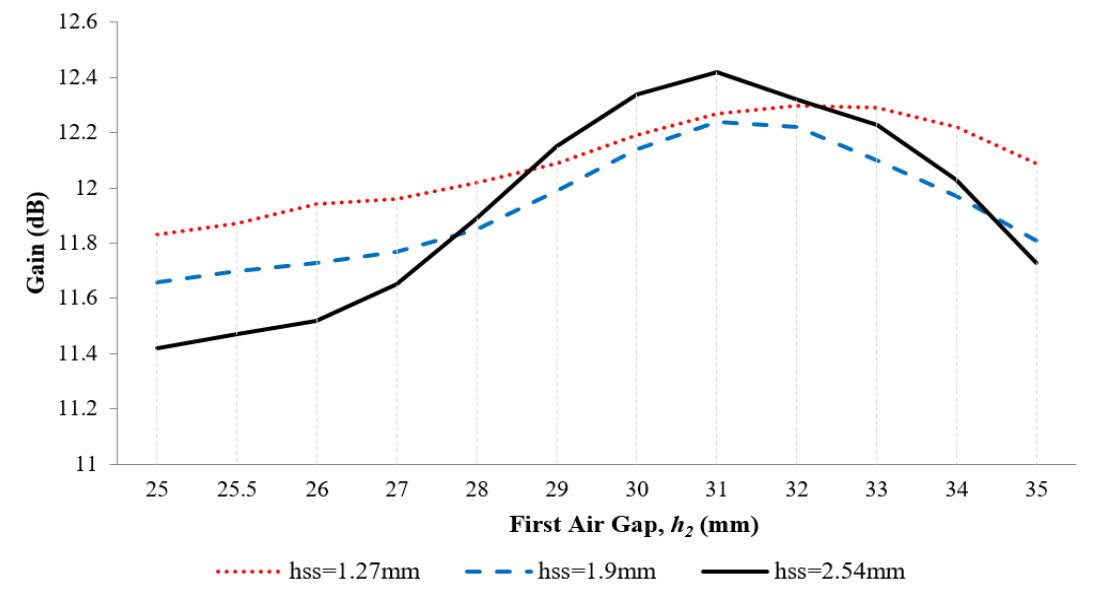

Figure 3. Gain variation versus the first air gap thickness $\left(h_{2}\right)$ for different superstrate thickness $\left(h_{s s}\right)$

Figure 4 depicts the simulated results for this experiment. From this figure, it can be observed that the gain values for $h_{3}$ of $3 \mathrm{~mm}$ which are shown in black solid line are higher than other lines. A maximum gain of $13.7 \mathrm{~dB}$ can be obtained at $h_{2}$ of $27 \mathrm{~mm}$, hence there is an extra gain of $1.28 \mathrm{~dB}$ after placing another superstrate above the first superstrate which is separated by air gap. It indicates that the OMYA with doublelayer is able to enhance the gain up to $2.5 \mathrm{~dB}$ compared to the OMYA without double-layer. It means that double superstrate concept can be used to enhance the gain of the OMYA due to the ability to focus the radiated electromagnetic energy and increase the gain of the OMYA.

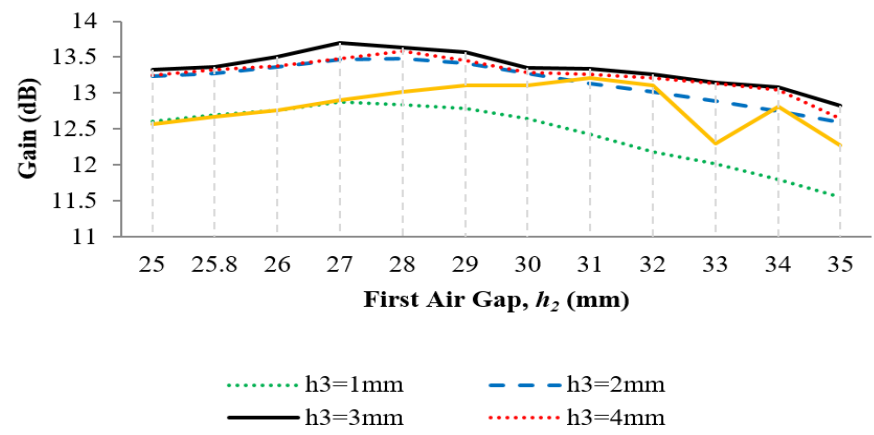

Figure 4. Gain variation with changing the first air gap height $\left(h_{2}\right)$ for different the second air gap height $\left(h_{3}\right)$

It can be noted that there is a limit on the values of $h_{2}$ and $h_{3}$. The gain will be suppressed if the $h_{2}$ and $h_{3}$ values become too large. As a result, the $h_{2}$ and $h_{3}$ values for the antenna in this research are $27 \mathrm{~mm}$ and $3 \mathrm{~mm}$, respectively. The simulated $S_{11}$ of the OMYA with double DPS layer having $h_{2}$ of $27 \mathrm{~mm}$ and $h_{3}$ of $3 \mathrm{~mm}$ is plotted in Figure 5. This plot shows that the antenna works in a frequency band from $5.48 \mathrm{GHz}$ to 
$6.32 \mathrm{GHz}$ with a center frequency of $5.8 \mathrm{GHz}$ and a wide bandwidth of $840 \mathrm{MHz}$ or $14.5 \%$ in fractional bandwidth.

Figure 6 portrays the simulated radiation patterns 3-Dimensional of the optimized OMYA with double-layer at $5.8 \mathrm{GHz}$. Through observing this figure, the OMYA with double-layer has capability to achieve a maximum gain up to $13.7 \mathrm{~dB}$ with the main lobe direction occurs in in E-Plane of $16^{\circ}$. It is interesting to note that the gain of the OMYA with double-layer is $2.5 \mathrm{~dB}$ higher compared to the OMYA without double-layer in [14], thus it gives evidence that double-layer can be used to enhance the gain. Table 2 summarize the optimized parameters of the OMYA with double-layer.

Table 2. The optimized parameters

\begin{tabular}{lc}
\hline \multicolumn{1}{c}{ Antenna Parameters } & Dimension $(\mathrm{mm})$ \\
\hline Air gap $\left(h_{2}\right)$ & 27 \\
Air gap $\left(h_{3}\right)$ & 3 \\
Superstrate Thickness $\left(h_{s s}\right)$ & 2.5 \\
Substrate Thickness $(h)$ & 1.575 \\
Total height of the proposed antenna $\left(H_{t}\right)$ & 39 \\
Total width of the proposed antenna $\left(W_{t}\right)$ & 70 \\
\hline
\end{tabular}

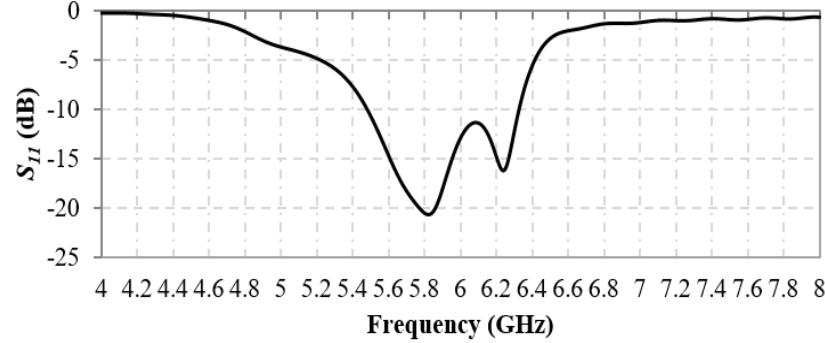

Figure 5. The simulated $S_{11}$ of the OMYA with double-layer

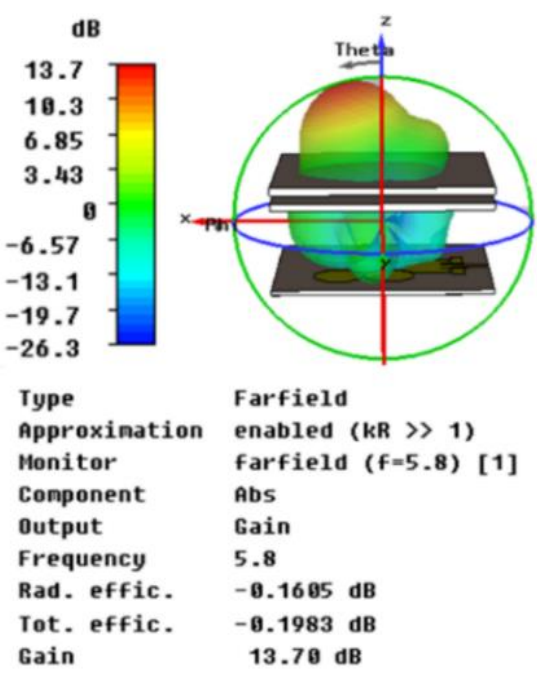

Figure 6. The simulated radiation patterns of OMYA with double-layer

The antenna prototype is shown in Figure 7. It can be seen that two high dielectric permittivity substrates are placed on the top of the OMYA and fixed using 4 plastic spacers at its 4 corners with plastic nuts. The two fabricated antennas was measured in order to validate the simulation models. An anechoic chamber at UTHM EMC Center - Batu Pahat was used to conduct the radiation pattern and gain measurements. Meanwhile, Anritsu 37347D vector network analyzer (VNA) was used to measure $S_{11}$.

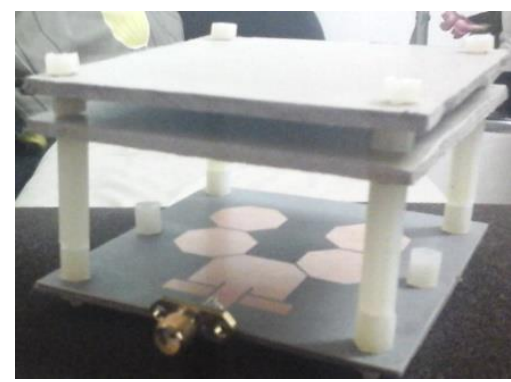

Figure 7. The prototype of the OMYA with double DPS layer 
Figure 8 plots the computed $S_{I I}$ of the proposed antenna in comparison with the measured $S_{I I}$ result over frequency range from $4 \mathrm{GHz}$ to $7 \mathrm{GHz}$. Black solid line corresponds to the measured $S_{11}$ has value below $-10 \mathrm{~dB}$ in a frequency band from $5.45 \mathrm{GHz}$ to $6.6 \mathrm{GHz}$, thus it has a fractional bandwidth of around $19.8 \%$ which is equal to a bandwidth of $1148 \mathrm{MHz}$. It is obviously seen that there is a discrepancy between the simulated and measured $S_{11}$ at upper frequency $\left(f_{u}\right)$ which the measured $f_{u}$ is shifted to $6.6 \mathrm{GHz}$. Hence, a deviation of $980 \mathrm{MHz}$ occurs at the upper frequency. It may be due to the amount of solder, the environmental factors such as noise and temperature of the room during measurement. Overall, the measured bandwidth of the fabricated antenna is wider than its simulated result by $35 \%$.

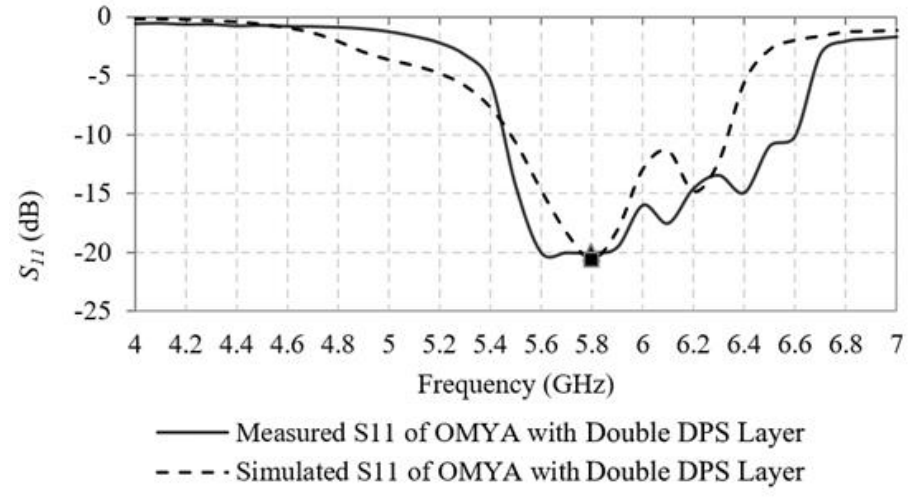

Figure 8 . The simulated and measured $S_{11}$

The experimental results for the radiation patterns are plotted in Figure 9. Black solid and dotted lines denote the measured and simulated radiation patterns, respectively. Figure 9 provides far field directivity of the antenna. With respect to Figure 9 (a), it shows the E-Plane of the antenna prototype has maximum radiation at an angle of about $10^{\circ}$ from broadside direction. On the other side, Figure 9 (b) shows the $H$-Plane of the proposed antenna. It can be observed that there is a small shift between the computed and the experimental results which is caused by fabrication imperfections, for instance, inaccuracy in placing the superstrate, etching process and connector soldering.

According to the measurement results, it was found that the antenna has a gain of $13 \mathrm{~dB}$. It indicates that a good agreement was achieved between the computed and measured results of the gain for this antenna, although the measured gain is about $0.7 \mathrm{~dB}$ lower than the simulated gain. It can be well observed from the results that the directive gain of the antenna can be enhanced by using double-layer with a proper choice of air gap thicknesses of $h_{2}$ and $h_{3}$ due to double-layer concept is able to concentrate the radiated waves in a small angle. However, it is obviously seen that there is a discrepancy between the simulated and measured $S_{11}$ and radiation patterns as shown in Figure 8 and Figure 9, respectively. It may be caused by fabrication imperfections and the environmental factors such as noise and temperature of the room during measurement. All the simulation and experimental results are summarized in Table 3.

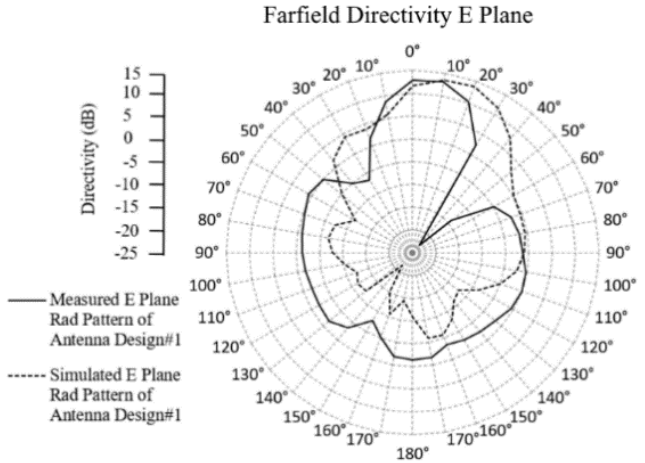

(a)

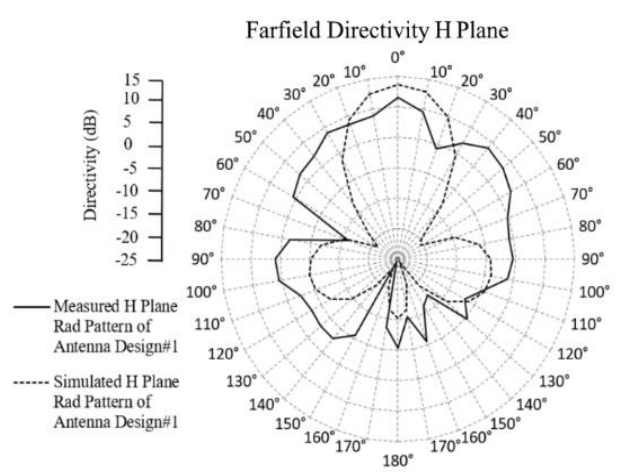

(b)

Figure 9. Far field directivity (a) $E$-field and (b) $H$-field 
Table 3. Comparison results of $S_{11}, B W$, and gain

\begin{tabular}{lccccc}
\hline \multicolumn{1}{c}{ Antenna Parameters } & $\begin{array}{c}\text { Centre Freq. } \\
(\mathrm{GHz})\end{array}$ & $\begin{array}{c}\mathrm{BW} \\
(\mathrm{MHz})\end{array}$ & $\begin{array}{c}\text { BW } \\
(\%)\end{array}$ & $\begin{array}{c}S_{11} \\
(\mathrm{~dB})\end{array}$ & $\begin{array}{c}\text { Gain } \\
(\mathrm{dB})\end{array}$ \\
\hline $\begin{array}{l}\text { Simulated OMYA } \\
\text { without double-layer (OMYA) }\end{array}$ & & 812 & 14 & -23 & 11.2 \\
$\begin{array}{l}\text { Simulated OMYA } \\
\text { with double-layer }\end{array}$ & 5.8 & 850 & 14.6 & -20.62 & 13.7 \\
$\begin{array}{l}\text { Fabricated OMYA } \\
\text { with double-layer }\end{array}$ & & 1148 & 19.8 & -20 & 13 \\
\hline
\end{tabular}

\section{CONCLUSION}

The OMYA is overlaid with double-layer was simulated, fabricated and measured in order to explore the influence of the double-layer on the OMYA performance. According to the simulation and measurement results, it shows that the double-layer is able to enhance the OMYA performance in term of gain and BW. The simulation result shows that the maximum fractional bandwidth of the OMYA without double-layer increased by $0.6 \%$ compared to the OMYA is overlaid with double-layer. One interesting finding is the bandwidth of the measured OMYA prototype is considerably larger than the simulated design. Therefore, it can be concluded that the bandwidth and gain of the OMYA can be increased by placing double-layer above the OMYA.

\section{ACKNOWLEDGEMENTS}

The author would like to express their heartfelt gratitude to Ministry of Higher Education and Indonesia Endowment Fund for Education (LPDP) for financing this research.

\section{REFERENCES}

[1] S. M. Shah et al., "A Compact dual-band semi-flexible antenna at $2.45 \mathrm{GHz}$ and $5.8 \mathrm{GHz}$ for wearable applications," Bulettin of Electrical Engineering and Informatics, vol. 10, no. 3, pp. 1739-1746, 2021, doi: 10.11591/eei.v10i3.226.

[2] H. Lehpame, "Microwave transmission networks - planning, design and deployment," New York: McGraw-Hill. 2004.

[3] M. Athavale, "Performance Analysis and Effect of Multiuser Interference for Ultra-Wideband Communications," M.S. thesis, Departmen Electrical Engineering, The University of Texas at Arlington, Arlington, Texas, 2008.

[4] A. A. Abdulbari et al., "Design compact microstrip patch antenna with T-Shaped 5G application," Bulettin of Electrical Engineering and Informatics, vol. 10, no. 4, pp. 2072-2078, 2021, doi: 10.11591/eei.v10i4.2935.

[5] K. Carver and J. Mink, "Microstrip antenna technology," IEEE Transactions on Antennas and Propagation, vol. 29, no. 1, pp. 2-24, January 1981, doi: 10.1109/TAP.1981.1142523.

[6] R. Garg, P. Bhartia, I. Bahl, and A. Ittipiboon, "Microstrip antenna design handbook," United State of America: Arthech House, 2000.

[7] V. F. Fusco, "Foundation of antenna theory and techniques," London: Person Education Limited, 2005.

[8] O. M. Haraz, A. Elboushi, S. A. Alshebeili and A. Sebak, "Dense Dielectric Patch Array Antenna With Improved Radiation Characteristics Using EBG Ground Structure and Dielectric Superstrate for Future 5G Cellular Networks," IEEE Access, vol. 2, pp. 909-913, 2014, doi: 10.1109/ACCESS.2014.2352679.

[9] N. Ghassemi and Sh. Mohanna, "Wideband Microstrip Array Antenna using Aperture Coupled Elements," Progress in Electromagnetics Research Symposium Proceedings, pp. 1177-1179, 2009.

[10] N. Ramli, M. T. Ali, M. T. Islam, A. L. Yusof and S. Muhamud-Kayat, "Aperture-Coupled Frequency and Patterns Reconfigurable Microstrip Stacked Array Antenna," IEEE Transactions on Antennas and Propagation, vol. 63, no. 3, pp. 1067-1074, March 2015, doi: 10.1109/TAP.2015.2388781.

[11] N. Bahari, M. F. Jamlos, and M. M. Isa, "Gain Enhancement of Microstrip Patch Antenna using Artificial Magentic Conductot," Bulettin of Electrical Engineering and Informatics, vol. 8, no. 1, pp. 166-171, 2019, doi: 10.11591/eei.v8i1.1409.

[12] J. Huang and A. C. Densmore, "Microstrip Yagi array antenna for mobile satellite vehicle application," IEEE Transactions on Antennas and Propagation, vol. 39, no. 7, pp. 1024-1030, 1991, doi: 10.1109/8.86924.

[13] G. R. DeJean and M. M. Tentzeris, "A New High-Gain Microstrip Yagi Array Antenna With a High Front-to-Back (F/B) Ratio for WLAN and Millimeter-Wave Applications," IEEE Transactions on Antennas and Propagation, vol. 55, no. 2, pp. 298-304, 2007, doi: 10.1109/TAP.2006.889818.

[14] K. Quzwain, A. Ismail, and A. Sali, "Compact High Gain and Wideband Octagon Microstrip Yagi Antenna," Electromagnetics, vol. 36, no. 8, pp. 524-533, 2016, doi: 10.1080/02726343.2016.1236060.

[15] O. Kramer, T. Djerafi and K. Wu, "Vertically Multilayer-Stacked Yagi Antenna With Single and Dual Polarizations," IEEE Transactions on Antennas and Propagation, vol. 58, no. 4, pp. 1022-1030, 2010, doi: 10.1109/TAP.2010.2041155. 
[16] P. S. Bhatnagar et al., "Experimental study on stacked triangular microstrip antennas," Electronics Letters, vol. 22, no. 16, pp. 864-865, Jul. 1986, doi: 10.1049/el:19860591.

[17] D. Jackson and N. Alexopoulos, "Gain enhancement methods for printed circuit antennas," IEEE Transactions on Antennas and Propagation, vol. 33, no. 9, pp. 976-987, 1985, doi: 10.1109/TAP.1985.1143709.

[18] X. H. Shen, G. A. E. Vandenbosch and A. V. Capelle, "Study of gain enhancement method for microstrip antennas using moment method," IEEE Transactions on Antennas and Propagation, vol. 43, no. 3, pp. 227-231, March 1995, doi: 10.1109/8.371990.

[19] K. Quzwain, A. Ismail, and A. Sali, "Octagon fractal microstrip Yagi antenna with a combined DNG and DPS layer structure," Microwave and Optical Letters, vol. 59, no. 8, pp. 1988-1993, 2017, doi: 10.1002/mop.30666.

[20] J. Joannopoulos, S. G. Johnson, J. N. Winn, and R. D. Meade, "Photonic Crystals: Molding The Flow of Light," New York: McGraw-Hill, 1995.

[21] M. Thevenot, C. Cheype, A. Reineix and B. Jecko, "Directive photonic-bandgap antennas," IEEE Transactions on Microwave Theory and Techniques, vol. 47, no. 11, pp. 2115-2122, 1999, doi: 10.1109/22.798007.

[22] E. Yablonovitch, "Inhibited spontaneous emission in solid-state physics and electronics," Physical Review Letters, vol. 58, no. 20, pp. 2059-2062, 1987.

[23] B. R. Franciscatto, A. C. Souza, C. Defay, T. T. Trang and T. P. Vuong, "High gain microstrip patch antenna array using multiple superstrate layers for DSRC applications," IEEE-APS Topical Conference on Antennas and Propagation in Wireless Communications APWC, 2012, pp. 736-739, doi: 10.1109/APWC.2012.6324937.

[24] H. Yang and N. Alexopoulos, "Gain enhancement methods for printed circuit antennas through multiple superstrates," IEEE Transactions on Antennas and Propagation, vol. 35, no. 7, pp. 860-863, 1987, doi: 10.1109/TAP.1987.1144186.

[25] Hung-Hsuan Lin, Chun-Yih Wu and Shih-Huang Yeh, "Metamaterial enhanced high gain antenna for WiMAX application," TENCON 2007 - 2007 IEEE Region 10 Conference, 2007, pp. 1-3, doi: 10.1109/TENCON.2007.4428876 